\title{
Developments in the management of autosomal dominant polycystic kidney disease
}

\author{
Amirali Masoumi \\ Berenice Reed-Gitomer \\ Catherine Kelleher \\ Mir Reza Bekheirnia \\ Robert W Schrier \\ Department of Medicine, Health \\ Sciences Center, University of \\ Colorado School of Medicine, Denver, \\ CO 80262, USA
}

\begin{abstract}
Autosomal dominant polycystic kidney disease (ADPKD) is the most frequent life- threatening, hereditary disease. ADPKD is more common than sickle cell anemia, cystic fibrosis, muscular dystrophy, hemophilia, Down's syndrome, and Huntington's disease combined. ADPKD is a multisystemic disorder characterized by the progressive development of renal cysts and marked renal enlargement. Structural and functional renal deterioration occurs in ADPKD patients and is the fourth leading cause of end-stage renal disease (ESRD) in adults. Aside from the renal manifestations, extrarenal structural abnormalities, such as liver cysts, cardiovascular abnormalities, and intracranial aneurysms may lead to morbidity and mortality. Recent studies have identified prognostic factors for progressive renal impairment including gender, race, age, proteinuria, hematuria, hypertension and increased left ventricular mass index (LVMI). Early diagnosis and better understanding of the pathophysiology of the disease provides the opportunity to aggressivly treat hypertension with renin-angiotensin-aldosterone system inhibitors and thereby potentially reduce LVMI, prevent cardiovascular morbidity and mortality and slow progression of the renal disease.
\end{abstract}

Keywords: hypertension, liver cysts, renal pain, left ventricular hypertrophy, cerebral aneurysms

\section{Introduction}

Autosomal dominant polycystic kidney disease (ADPKD) is characterized by renal cyst enlargement, resulting in abnormal kidney structure and renal insufficiency. End stage renal disease (ESRD) will be observed in $50 \%$ of cases by the fifth decade. ADPKD is the most common life- threatening, hereditary disease, which affects 1:400 to 1:1000 live births (Ecder et al 2006). The incidence of ADPKD is more frequent than sickle cell anemia, cystic fibrosis, muscular dystrophy, hemophilia, Down's syndrome, and Huntington's disease combined (PKD Foundation 2000). ADPKD is genetically heterogeneous with separate loci on chromosome 16 (PKD1), accounting for approximately $85 \%$ of ADPKD cases, and on chromosome 4 (PKD2), accounting for approximately $15 \%$ of patients (Kimberling et al 1993).

Numerous renal and extra-renal manifestations have been described for ADPKD. Hypertension, left ventricular hypertrophy, cardiac valvular defects, back and abdominal pain, cerebral aneurysms, and liver cysts are the most important clinical findings. There are several risk factors, which affect the progression of renal disease such as gender, race, age, renal volume, hypertension, proteinuria and hematuria (Gabow et al 1992). It has been shown that the disease is more severe in PKD1 patients as compared to PKD2. Hypertension and proteinuria are more pronounced in PKD1 patients (Chapman et al 2003; Grantham et al 2006a). In both PKD1 and PKD2, older patients generally have more cysts, indicating that the cystogenesis continues throughout the life of patients. Renal volume is highly associated with hypertension and both have significant impact on renal outcomes (Fick-Brosnahan et al 2002; Schrier et al 2003). Recently it has 
been defined that the rate of cyst growth is comparable in PKD1 and PKD2. However, the number of cysts is greater in PKD1 patients (Harris et al 2006). Male, as compared to female, patients of European descent tend to have more severe disease with faster expansion of cyst volumes. There are some preliminary results indicating that African-Americans exhibit worse disease than ADPKD patients of European descent (Gabow et al 1992). Understanding the natural history of the disease, clinical risk factors and targeting the treatable aspects of the disease are the main foci in order to choose the appropriate interventions.

\section{Diagnosis}

The diagnosis of ADPKD is usually made by family history and renal imaging. In the case of affected family members gene linkage analysis has been used. However, genetic studies are expensive but may be employed if the diagnosis is uncertain and renal imaging is not informative. A recent study showed that physicians and patients' awareness of the hereditary basis of ADPKD has led to better family histories and an earlier diagnosis of ADPKD (Taylor et al 2005). Earlier diagnosis could have beneficial effects with interventions to slow renal disease progression and prevent cardiovascular complications in ADPKD patients. In recent years, with the widespread availability of ultrasonography, this modality has been established as the main radiologic technique for diagnosis of ADPKD (Elles et al 1994; Gabow et al 1997). In one study ultrasonograghy was found to be more reliable in patients older than 30 years and especially in PKD1 (Nicolau et al 1999). Diagnostic criteria based on US findings in individuals with positive family history are shown in Table 1.

In 2002, Fick et al demonstrated that total kidney volume and renal cyst volumes were strongly correlated with the decline of glomerular filtration rate (GFR) (Figure1) (Fick-Brosnahan et al 2002; Chapman et al 2003). A recent national study conducted by the Consortium of Radiologic Imaging Studies of Polycystic Kidney Disease (CRISP) provides support for this view (Grantham et al 2006b). They have shown that cystic growth rate is highly variable among ADPKD patients but it is mostly a progressive process during

Table I Criteria for diagnosing autosomal dominant polycystic kidney disease (ADPKD) by renal ultrasound

\begin{tabular}{ll}
\hline Age (years) & Criteria \\
\hline$<30$ & At least 2 renal cysts (Unilateral or Bilateral) \\
$30-59$ & At least 2 cysts in each kidney \\
$\geq 60$ & At least 4 cysts in each kidney \\
\hline
\end{tabular}

the course of the disease. Patients with larger kidneys have the fastest rates of renal volume enlargement (Grantham et al $2006 b)$. Thus, measurement of renal volume is of clinical relevance. Although ultrasonography is safe, easily performed, available and inexpensive, it is not precise enough to detect short-term disease progression (O’Neill et al 2005). Magnetic resonance imaging $(\mathrm{MRI})$ has been shown to be more sensitive and reliable for measurement of the renal cyst volume. In contrast to ultrasonograghy, MRI is being evaluated as a useful technique to determine the cystic changes over a short time period (Chapman et al 2003).

\section{Hypertension}

Hypertension is the most frequent complication among ADPKD patients, occurring in approximately $60 \%$ of the patients, while their glomelural filtration rate (GFR) is still in the normal range (GFR $>75 \mathrm{~mL} / \mathrm{min} / 1.73 \mathrm{~m}^{2}$ ) (Gabow, Chapman et al 1990; Chapman et al 1991). Compared to the general population hypertension occurs at a much earlier age in ADPKD patients (Kelleher et al 2004). The median age at hypertension diagnosis in ADPKD was found to be 32 years for males and 34 years for females (Figures $2 \mathrm{a}$ and $2 b)$. The occurrence of hypertension is greater in both male and female ADPKD patients when their affected parents are hypertensive. Moreover, the age of diagnosis of hypertension is also earlier in ADPKD patients with affected hypertensive parents (Schrier et al 2003). Several studies have shown that hypertension in ADPKD patients is associated with increased renal volumes and left ventricular mass index (LVMI), in both adults and children (Sedman et al 1987; Chapman et al 1997; Gabow et al 2006a). Hypertension and LVMI are important risk factors for cardiovascular disease, which is the most common cause of death in patients with ADPKD (Fick et al 1995).

Angiographic studies have demonstrated that cyst enlargement in ADPKD is associated with compression of the adjacent parenchyma and vasculature, with resultant areas of renal ischemia (Ettinger et al 1969). Several studies have shown elevated concentrations of renin in both tissue and cyst fluid from ADPKD patients (Torres et al 1992). Further studies have indicated an intrarenal role of RAAS by detecting the angiotensinogen, angiotensin-converting enzyme (ACE), angiotensin II type 1 (AT1) receptor, and angiotensin II within cysts and tubules of ADPKD kidneys (Loghman-Adham et al 2004). These results support activation of the renin-angiotensin-aldosterone system (RAAS) secondary to renal ischemia. The first clue of RAAS activation in ADPKD arose from clinical studies, 


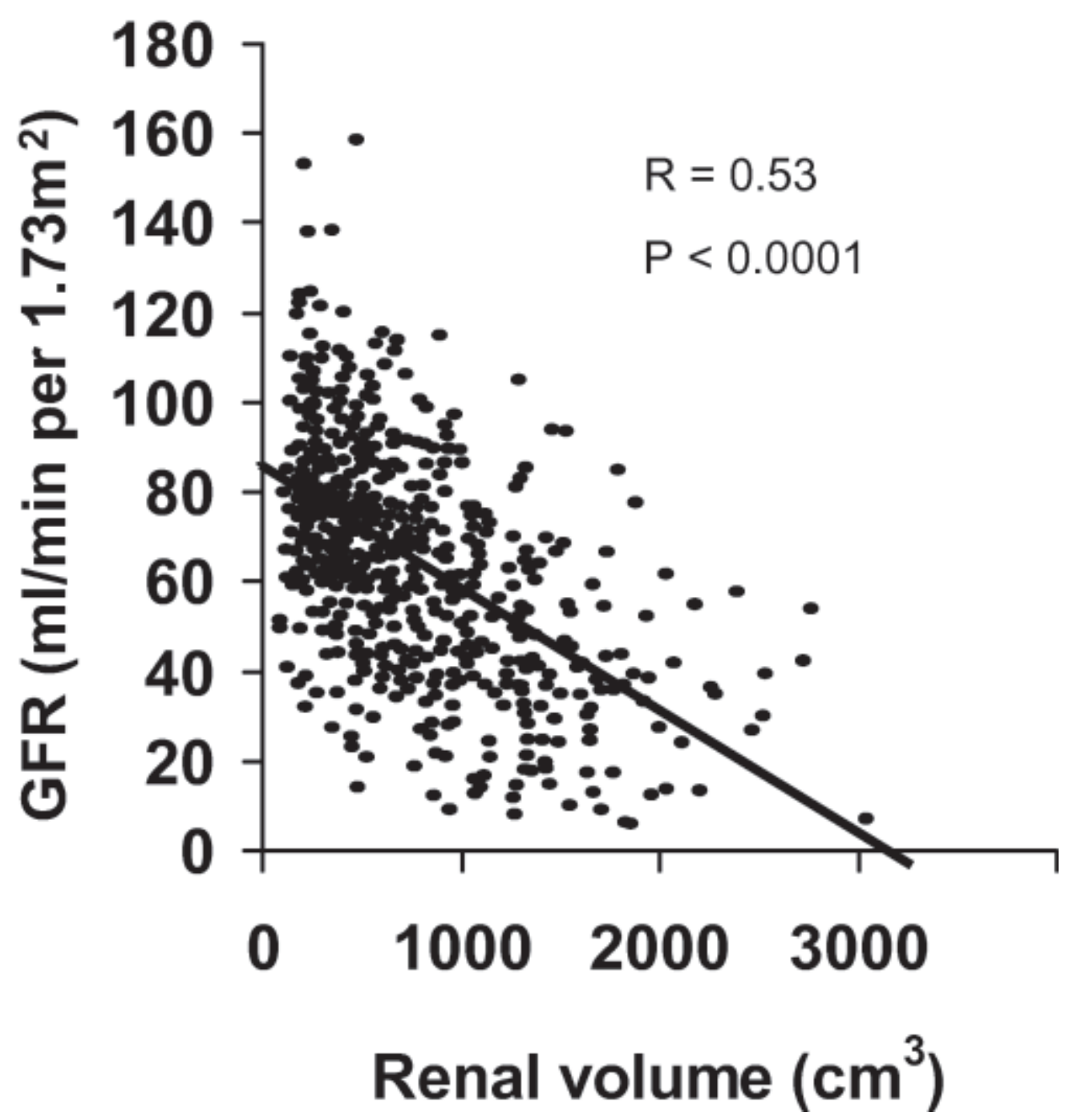

Figure I Correlation between GFR and renal volume in ADPKD patients.

which demonstrated an increase in the plasma renin activity (PRA) with captopril, an ACE inhibitor, in hypertensive, but not normotensive patients with ADPKD (Anderson et al 1979; Torres et al 1991). Since an increase in blood pressure may decrease PRA, a comparison of the RAAS in patients with essential hypertension and hypertensive ADPKD patients who were matched was undertaken at comparable blood pressure (BP), renal function, age, and sodium intake. These studies demonstrated significantly higher PRA and plasma aldosterone concentrations in the supine and upright positions, as well as after ACE inhibition, with captopril in the ADPKD patients as compared to essential hypertension patients. In addition, after six weeks of ACE inhibition with enalapril, ADPKD hypertensive patients exhibited a significant increase in renal plasma flow due to decrease in renal vascular resistance and consequently a decrease in filtration fraction rate as compared to essential hypertension patients (Watson et al 1992; Ecder et al 2001). In a retrospective study, ADPKD hypertensive patients received either ACE inhibitor or diuretics. During a mean follow-up of 5 years, patients who were treated with diuretics without any ACE inhibitors had a greater decrease in GFR and an increase in serum creatinine levels compared with patients who were taking only ACE inhibitors. Although systolic or diastolic blood pressure at baseline or at the end of the survey showed no differences, the diuretic group needed more additional antihypertensive drugs for comparable blood pressure control than the ACE inhibition group (64 vs 21\%, p < 0.05) (Ecder et al 2001). In an epidemiological paper, it was shown that the risk for male ADPKD male patients entering end stage renal disease (ESRD) is 10 times higher among those with a mean arterial 

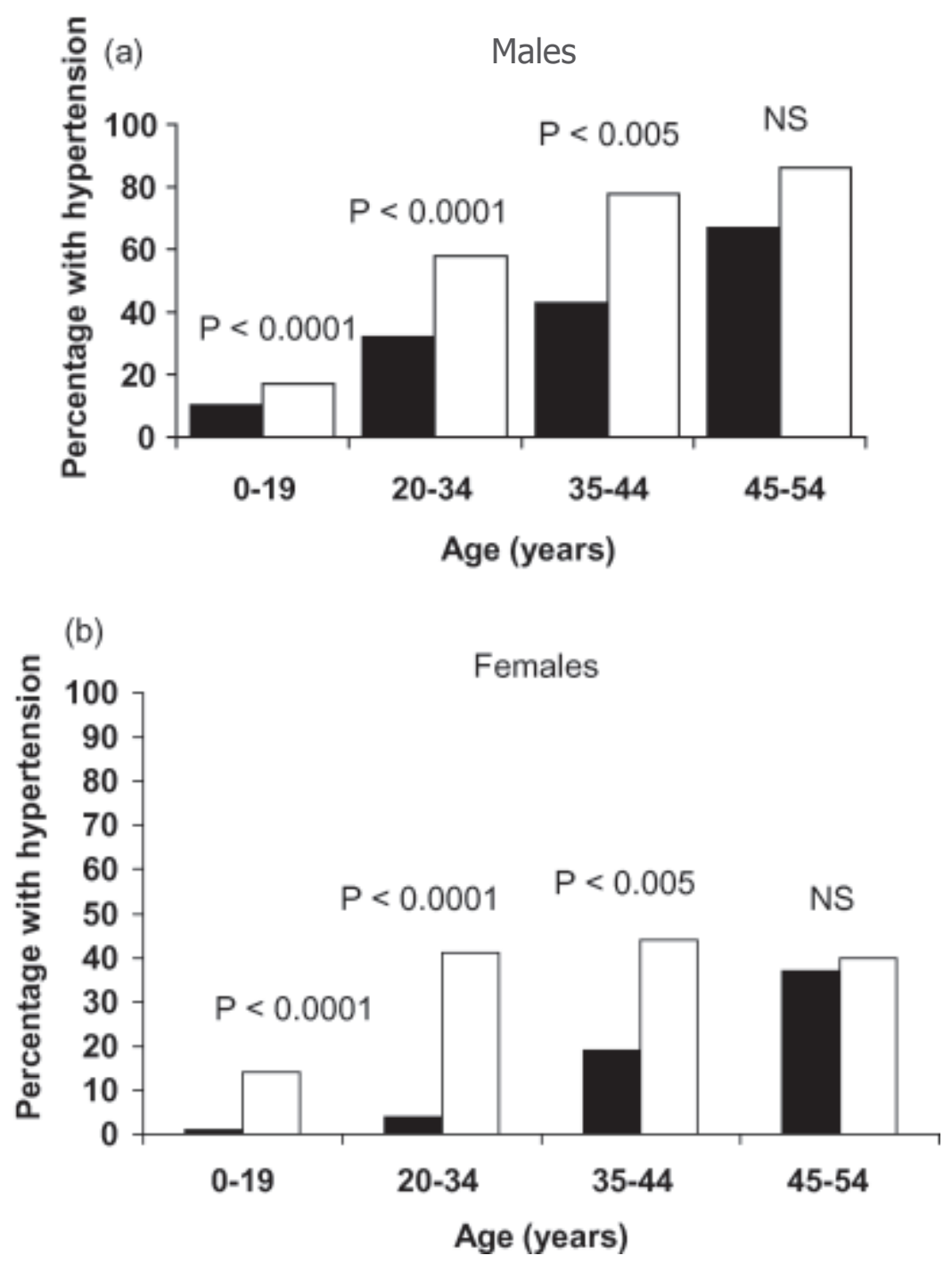

Figure 2 Prevalence of hypertension in autosomal dominant polycystic kidney disease ( $\square$ ) in (a) males and (b) females I995-2000 vs NHANES IV ( $\square$ ).

pressure (MAP) greater than $93 \mathrm{~mm} \mathrm{Hg}(>120 / 80 \mathrm{~mm} \mathrm{Hg}$ ) compare to those patients with a MAP less than $93 \mathrm{~mm} \mathrm{Hg}$. A similar analysis estimated that female ADPKD patients with a MAP greater than $93 \mathrm{~mm} \mathrm{Hg}$ were 2.4 times more likely to progress to ESRD than those patients with MAP of $93 \mathrm{~mm} \mathrm{Hg}$ or less. Further, when ADPKD patients from 1985-1992 were compared with ADPKD patients from 1992-2001, a later age of ESRD onset was observed in the more recent group in which more aggressive control of hypertension has been emphasized (Figure 3) (Schrier et al 2003).

\section{Left ventricular hypertrophy}

As already noted, in the era of renal replacement therapy with dialysis or transplantation, cardiovascular disease is the leading cause of death in patients with ADPKD (Fick et al 1995). One important risk factor is left ventricular hypertrophy (LVH), which exacerbates cardiac morbidity and mortality in patients with other types of disease. Due to early onset of hypertension in ADPKD patients, a significant correlation between LVH and mean arterial pressure may be seen (Figure 4). Left ventricular mass index (LVMI) is highly related to systolic blood pressure in ADPKD (Bardaji et al 1998). In 116 ADPKD patients in their early 40 s, LVH was found in $46 \%$ of male and $37 \%$ in female patients. LVH has also been detected in $23 \%$ of ADPKD patients with normal blood pressure (Chapman et al 1997; Ecder et al 2001). This may be due to the observation that BP may not decrease at night in ADPKD patients, ie, non-dippers.

A prospective study demonstrated that ACE inhibition with enalapril controlled BP and reversed LVH in hypertensive ADPKD patients (Ecder et al 1999). A recent randomized 
(a)

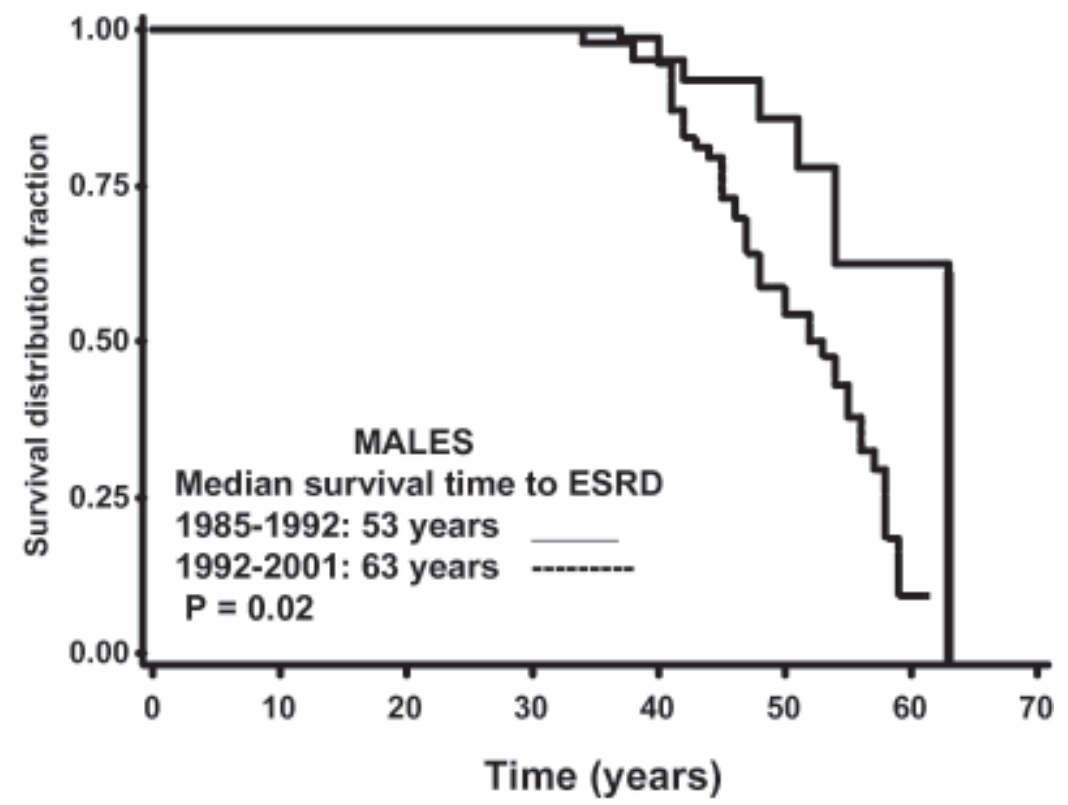

(b)

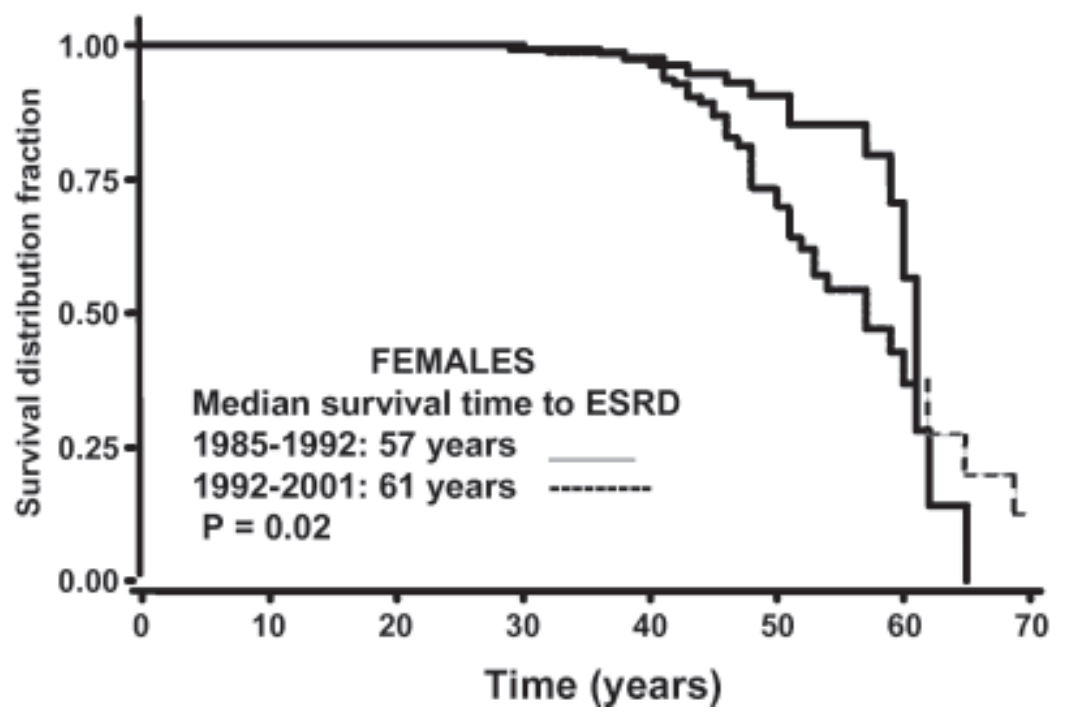

Figure 3 Survival Curves for end-stage renal failure (ESRD) in (a) male and (b) female ADPKD patients from 1985-1992 vs 1992-2001 ( $\mathrm{n}=97)$.

prospective study on 75 hypertensive ADPKD patients with LVH demonstrated that rigorous BP control $(<120 / 80 \mathrm{mmHg})$ versus standard (135-140/85-90 mmHg) BP control over a 7-year follow-up period had a significantly greater reversal of LVH. Both standard and rigorous BP control groups had decreased LVH, but LVMI was returned to the normal range in more patients in the rigorous BP control group than in the standard BP group (71\% vs. 44\%) (Figure 5). Moreover, patients receiving the ACE inhibitor enalapril had a greater decrease in LVMI as compared to those who received amlodipine, a calcium channel blocker (Ecder at al 1999;
Schrier et al 2002). Thus, the use of an ACE inhibitor and maintenance of a blood pressure goal at $120 / 80 \mathrm{mmHg}$ in hypertensive ADPKD patients with LVH should be undertaken (Ecder and Schrier 2004). Another study was conducted among 20 hypertensive ADPKD patients compared with an age-and sex-matched essential hypertensive subjects designated as a control group. Both groups had the same 24 hour ambulatory BP and LVMI, although male ADPKD patients had higher LVMI than their matched controls. LVH was detected in $40 \%$ of ADPKD patients compared to $30 \%$ of the essential hypertensive group. ADPKD patients with $\mathrm{LVH}$ did not differ 


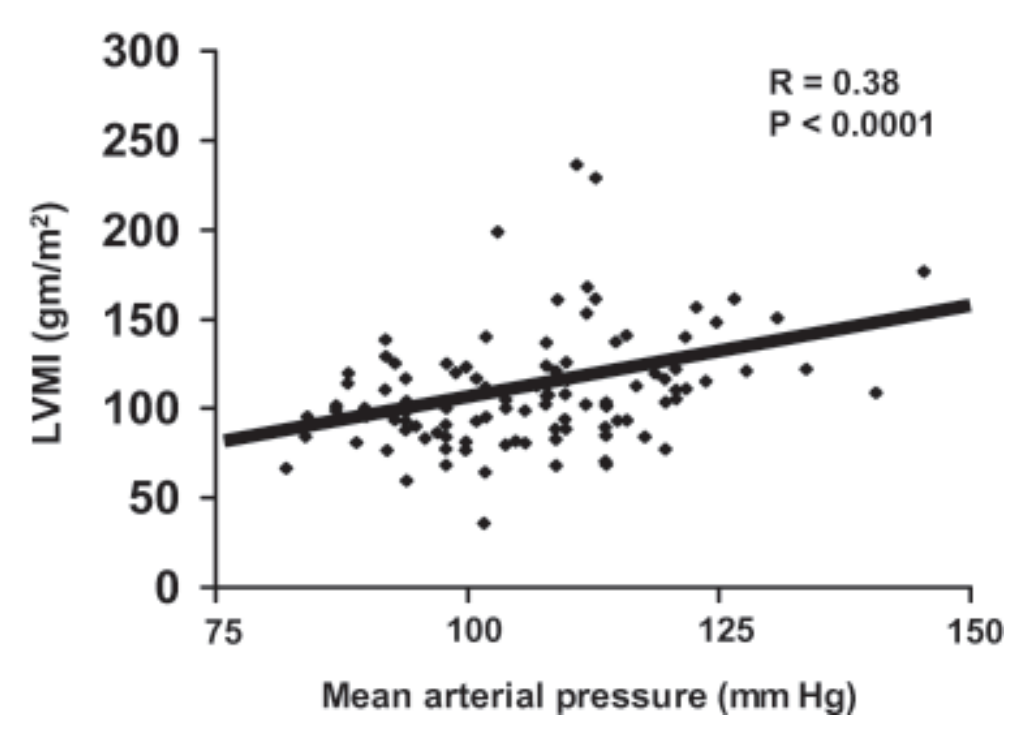

Figure 4 Correlation between blood pressure and left ventricular hypertrophy in ADPKD patients.
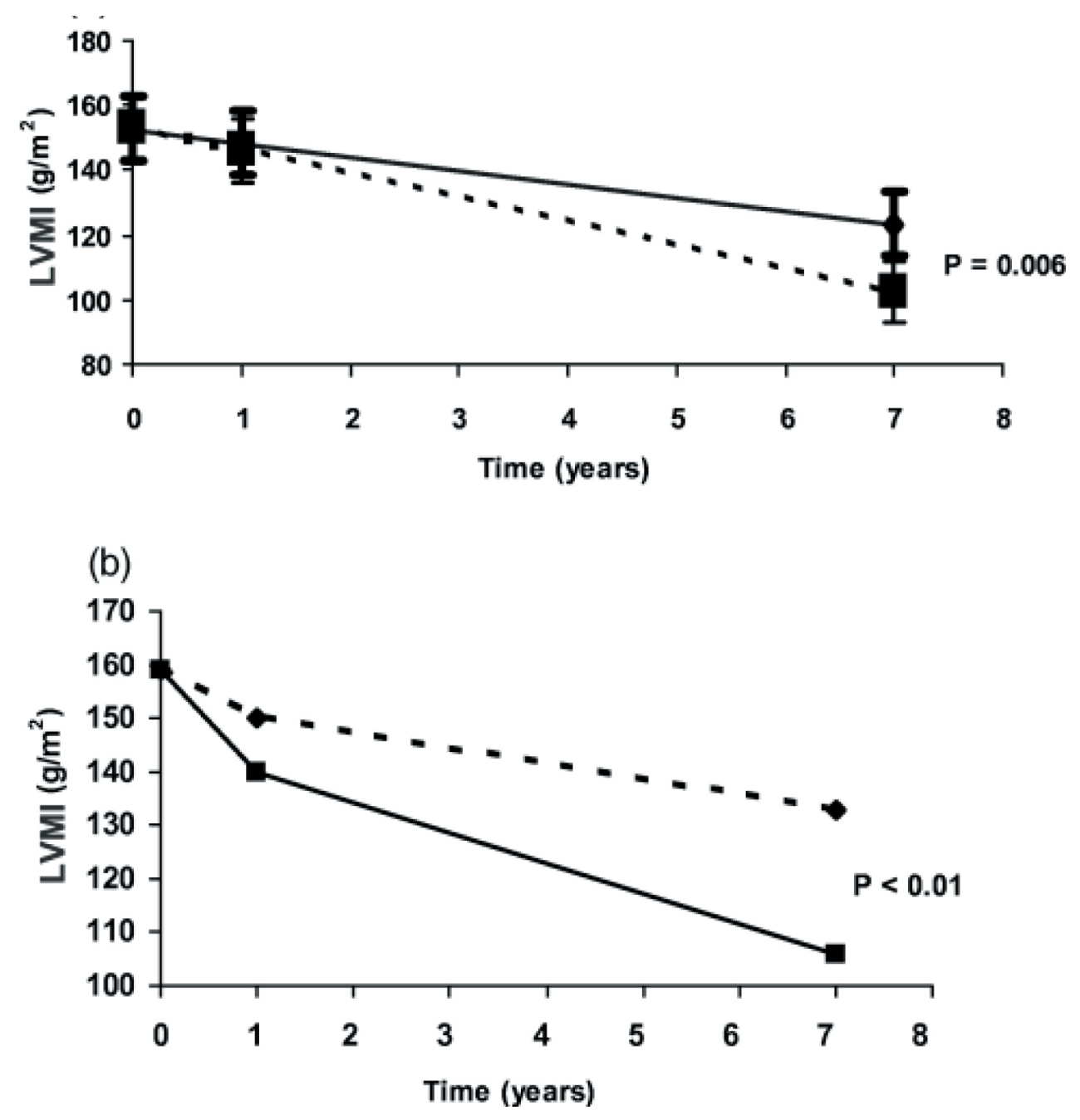

Figure 5 (a) Effect of rigorous ( $\square$ ) versus standard ( $\bullet$ blood pressure control to decrease left ventricular mass index in autosomal dominant polycystic kidney disease $($ ADPKD) patients. (b) Effect of blood pressure control with amlodipine $(\bullet)$ versus enalapril $(\boldsymbol{\square})$ to decrease left ventricular mass index in ADPKD patients. 
from those without LVH, except that they had higher 24-hour ambulatory BP levels. This study indicates a correlation between LVMI and 24-hour systolic and diastolic blood pressure in ADPKD patients (Martinez et al 2000). ADPKD patients may demonstrate insulin resistance (Hjelmesaeth and Hartmann 1999), thus studies have been conducted to determine the prevalence of LVH among these patients. Results showed a significant association between LVMI and insulin resistance independently of other factors such as age, weight, systolic blood pressure and albuminuria (Lumiaho et al 2003). The stimulation of angiotensin II (Rocchini et al 1990) and the sympathetic nervous system secondary to elevated insulin levels therefore may have a major role in increased LVMI in ADPKD patients (Lembo et al 1992).

In addition to $\mathrm{LVH}$, valvular disorders are common among ADPKD patients. It has been shown that the prevalence of mitral valve prolapse (MVP) is higher in ADPKD patients as compared to general population ( $26 \%$ vs $2 \%$ ). ADPKD patients also have an increased risk of tricuspid valve prolapse $(6 \%)$. Mitral and aortic incompetence also has been detected more frequent in ADPKD patients (31 and 8 percent respectively) (Hossack et al 1988; Timio et al 1992; Martinez-Vea 1999).

\section{ADPKD in children}

ADPKD is usually considered an adult disease. In the 1970 s and 1980 s cases of early disease in children and even in utero were described (Blyth and Ockenden 1971; Kaye and Lewy 1974; Bengtsson et al 1975; Garel et al 1983; Pretorius et al 1987). Thus, modern imaging techniques, especially renal ultrasonograghy, emerged as the procedure to diagnose ADPKD. In one study approximately $60 \%-90 \%$ of PKD gene carriers under the age of 20 years were recognized by renal ultrasonograghy (Sedman et al 1987). Recently, it has been shown that the sensitivity of ultrasonograghy in ADPKD patients younger than 30 years is almost 95\% (Nicolau et al 1999). In a study on PKD-1 gene mutation carriers, among $0-5$-year-old children, renal cysts were detected in $60 \%$ of the study group by ultrasound. In children aged 5-18 years, $75 \%-80 \%$ had detectable cysts by renal ultrasound (Gabow et al 1997). ADPKD children, in addition to their renal cysts, may present with a variety of clinical findings, ranging from newborns with severe disease including massive renal enlargement, hypertension, oliguria, and pulmonary hypoplasia to the absence of signs or symptoms (Mcdonald et al 1999). Unlike adults, the factors in children, which have an impact on the disease progression, are not well understood (Fick et al 1994). GFR is not a reliable predictor of disease progression in children (Fick et al 1993). Fick et al in an observational study on 312 children described the characteristics, which are associated with faster renal volume growth. Risk factors were renal enlargement in utero or the first year of life, high blood pressure and the presence of more than 10 renal cysts before age 12 years. The rate of renal enlargement may be a relevant marker for disease progression. However, there is considerable variability in renal volumes among affected children. Nevertheless, at any given age, the affected children had significantly larger kidneys as compared to non-affected children (Fick et al 2001).

Most ADPKD children have less than 10 cysts before 12 years of age, but children with more than 10 cysts generally have more severe disease. The prevalence of high blood pressure and flank and/or back pain is higher in the children with more cysts and larger kidneys. Polyuria and impaired urinary concentration are also associated with larger kidneys (Fick et al 1994). Children with more than 10 cysts, compared to children with less than 10 cysts, had a greater annual increase in renal volumes even though they were younger at their first and last visits. Evaluating the number of renal cysts might be more practical in children than measuring age-adjusted renal volumes. Also children with higher blood pressure exhibited greater renal growth rate. In contrast to adults, in children gender distribution does not seem to have an impact on renal disease progression rate (Fick et al 2001).

In a recent $\mathrm{ADPKD}$ study in children, those cases with very early onset of disease (VEO) (ie, diagnosed before 18 months of life) and children diagnosed between 18 months and 18 years of age (non-VEO) have been evaluated and compared. When adjusted for age, the VEO group had larger renal volumes, more frequent hypertension, and higher serum creatinine, lower creatinine clearance and estimated GFR compared with non-VEO children. LVMI was also greater in VEO children (Figure 6). Proteinuria, hematuria, and symptoms at diagnosis in both groups were correlated with significantly larger age-adjusted renal volumes (Shamshirsaz et al 2005). Interestingly, over $90 \%$ of VEO children maintained preserved renal function well into childhood and in general their growth was normal (Sedman et al 1987; Taitz et al 1987; Fick et al 1993; Shamshirsaz et al 2005). However, because of the potential for severe complications such as hypertension and renal insufficiency, these children should be closely and regularly monitored. Due to the significant association between larger kidneys and early progression to ESRD, the beneficial effects of reducing renal growth and LVMI by RAAS blockers was considered important. Such a prospective study is underway at the University of Colorado Health Sciences Center. 


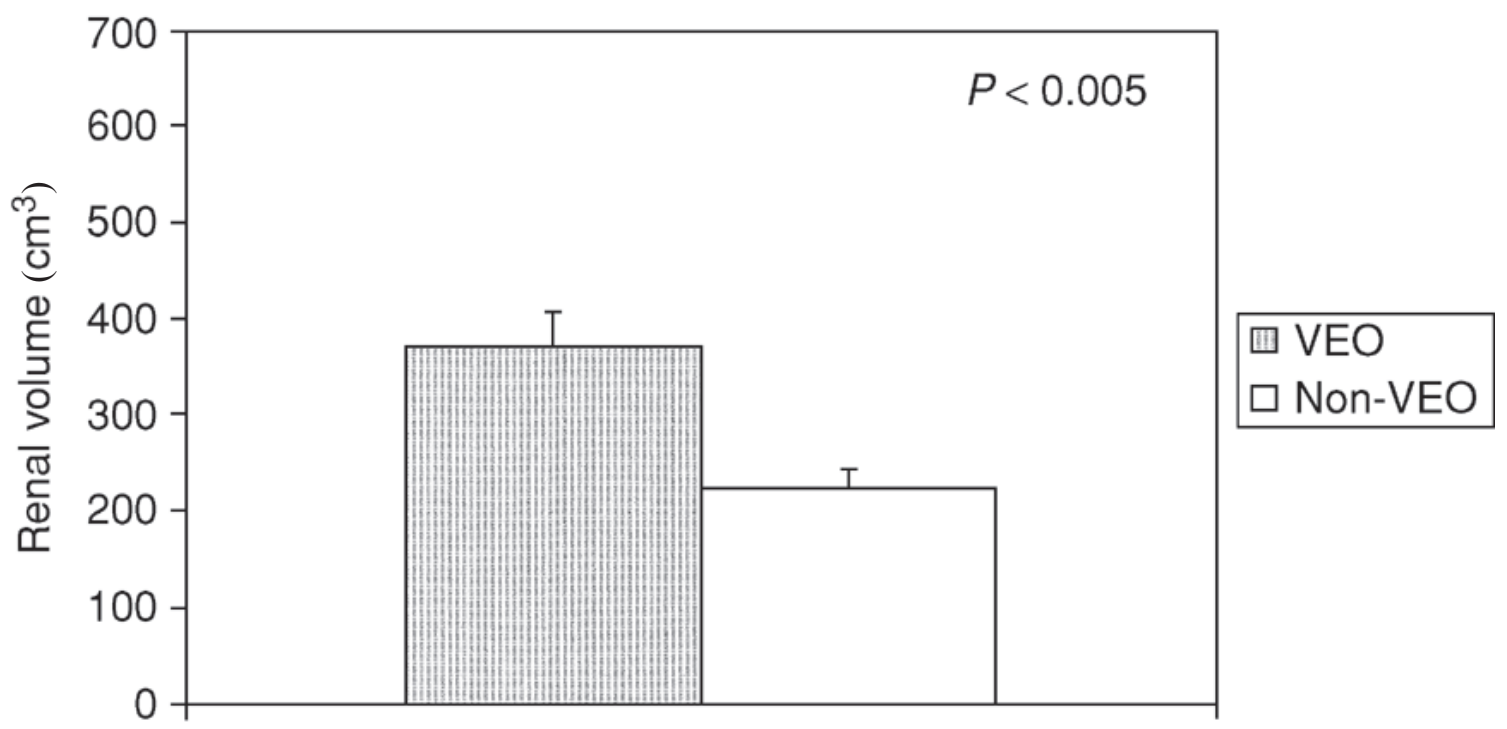

Figure 6 Renal volumes in age-adjusted VEO children and non-VEO children.

Similar to the adult population with ADPKD, there is also a greater prevalence of MVP among the pediatric population (Ivy et al 1995). Leier at al (1984) reported that $36 \%$ of ADPKD patients have bicuspid aortic valve, but the prevalence of congenital cardiac diseases in adults with ADPKD is unknown.

\section{Proteinuria}

The presence of proteinuria may be an indicator of subclinical end-organ damage in addition to kidney damage, including the presence of LVH and systemic atherosclerosis. Recent studies have shown significant association between LVMI and proteinuria (Leoncini, Viazzi et al 2002; Leoncini, Sacchi et al 2002; Pontremoli et al 2002). Microalbuminuria (30-300 mg/24 h in adults), a sensitive measure of urinary albumin excretion, has been useful in identifying the risk of developing diabetic nephropathy. It has also been positively related to an increased risk of cardiovascular mortality in essential hypertensive patients, especially old, obese, and male patients. In ADPKD patients, proteinuria is considered to be an important predictor of renal disease progression. In a study of 270 ADPKD patients only $18 \%$ of cases presented with established proteinuria ( $>300 \mathrm{mg} /$ day). Interestingly all these patients had hypertension and also had large renal volumes. Renal functional impairment was greater in these patients who also showed a faster tendency for disease progression and an increased incidence of hematuria (Chapman et al 1994). Furthermore, $41 \%$ of hypertensive ADPKD patients with LVH showed some degree of microalbuminuria (30-300 mg/24 h). These patients with microalbuminuria and LVH had higher
MAP (MAP 107 vs 113, p < 0.005) and renal volumes (535 vs $853 \mathrm{~cm} 3, \mathrm{p}<0.01$ ) (Ecder et al 2001). A 5-year prospective, randomized study of 24 ADPKD patients was conducted to examine the antialbuminuric effect of amlodipine, a calcium channel blocker, versus enalapril, an ACE inhibitor, on urinary albumin/creatinine ratio. Albumin to creatinine ratio increased significantly in the amlodipine related patients, but was stable in the enalapril-treated ADPKD patients at comparable levels of BP control. (Ecder et al 2000) Thus, we can tentatively propose that the sustained antialbuminuric effect of ACE inhibitors may improve the long-term renal and cardiovascular prognosis in ADPKD patients.

\section{Pain}

The most frequent complaint in ADPKD patients is pain, occurring in approximately $60 \%$ of patients (Gabow 1990). Severe abdominal and flank pain is a known frustrating experience among ADPKD patients (Mulutinovic et al 1984; Mulutinovic et al 1990). In a recent study of 171 ADPKD patients, $71.3 \%$ reported lower back pain, which was the most common pain pattern in this group. $29.6 \%$ of this group had radiculopathy symptoms. Abdominal pain was seen in $61.4 \%$ of these patients. The abdominal pain was described as dull pain (49.5\%), uncomfortable fullness (42.7\%), stabbing pain (40.4\%), and cramping (33.0\%) (Bajwa et al 2004). This pain can occur both acutely or persist on a chronic basis.

\section{Acute pain}

Cyst rupture or hemorrhage, infected cysts and renal stones are considered as the most common etiologies of acute 
pain. (Bajwa et al 2001) Generally, urinary tract infections (UTI) are seen in about $60 \%-70 \%$ of adult women and $20 \%$ of men with ADPKD (Milutinovic et al 1984, 1990; Sklar et al 1987). The most frequent clinical presentation is cystitis, which is treated in the same manner as in the general population. Infected renal cysts may result in symptoms of pyelonephritis. Fever and or flank pain are common findings in both pyelonephritis and cyst infection. However, with cyst infection, a low-grade fever in association with localized flank pain is a common pattern. The pain does not radiate and is not relieved by positioning (Bajwa et al 2001). Unlike pyelonephritis, urinalysis and cultures may be negative with cyst infection, whereas blood cultures are positive in most of the cases (Sklar et al 1987). Although infected cysts may be difficult to diagnose, contrast enhanced CT or MRI and scintigraphy with indium-111 labeling of leukocytes are the best imaging methods (Bretan et al 1988; Chapman et al 1990). Since highly ionized, water-soluble antibiotics like penicillins and cephalosporins do not readily penetrate the renal cyst cavities, they are not effective in ADPKD. Treatment of infected ADPKD cysts should consist of lipophilic agents such as clindamycin, ciprofloxacin, norfloxacin, and trimethoprim- sulfamethoxazole. In most cases therapy should continued for 6 weeks. (Bennett et al 1985) In resistant cases, cyst drainage may be needed (Chapman et al 1990). Inadequate treatment of UTI in ADPKD may lead to perinephric abscess with consistent pain and more serious complications needing surgical interventions (Sweet and Keane 1979).

The prevalence of nephrolithiasis in ADPKD adult patients ranges from $20 \%$ to $36 \%$ (Torres et al 1988; Gambaro et al 2006). Twenty to $28 \%$ of these patients are symptomatic (Milutinovic et al 1990; dimitraovand Simeonov 1994), thus a substantial portion of these ADPKD patients with nephrolithiasis may be asymptomatic (Levine and Grantham 1992). Flank pain, hematuria and UTI are presentations of nephrolithiasis in ADPKD. The most common renal stones in ADPKD are uric acid stones (50\%), which is a much higher incidence compared to the general population (Levine and Grantham 1992; Daudon et al 2003). The low prevalence of stones containing calcium, such as calcium oxalate, suggests a minor role of hypercalciuria and hyperoxaluria (Torres et al 1993). Stone formation in ADPKD patients mostly relates to metabolic defects, and/or urinary stasis within structural abnormalities due to cyst compression. Hypocitraturia has been found to be the most important metabolic factor, occurring in approximately $60 \%$ and $49 \%$ of ADPKD patients with and without stones respectively
(Torres et al 1993; Grampsas et al 2000). In the same study Grampsas et al (2000) have reported that the stone-forming ADPKD patients have higher cyst numbers and also larger cysts compared to non-stone formers. These findings support the theory that cyst enlargement with secondary distortion of the renal collecting system contributes to stone formation, probably through the mechanism of urine stasis (Torres et al 1993). Because of the nature of the stone-related urinary tract obstruction and distension, pain is a very common symptom. Short-term administration of non-steroidal antiinflammatory drugs (NSAIDs) (limited to two to three days) in ADPKD patients suffering from renal colic can be helpful (Hetherington and Philp 1986; Osterlinck et al 1990; McIntire et al 1993). These agents may decrease the inflammation and edema, and thereby facilitate stone passage. Although opioids are still a basic analgesic for renal colic therapy, a large number of studies have demonstrated no differences between the usage of NSAIDs and opioids in the treatment of renal calculi. It has been shown that extracorporeal shock wave lithotripsy (ESWL) and nephrolithotomy may provide favorable results in symptomatic ADPKD patients with renal calculi (Anderson et al 1993; Chen et al 1993; Torres et al 1993; Delakas et al 1997).

Renal cyst rupture in ADPKD may present with acute colicky pain, usually associated with gross hematuria (Dalgaard 1957). Approximately $42 \%$ to greater than 50\% of ADPKD patients have experienced at least one episode of gross hematuria (Rovitch et al 1976; Gabow, Duley and Johnson 1992). In 20\% of ADPKD patients gross hematuria was the initial diagnostic clue. UTI is the most frequent cause of gross hematuria, especially among women. Sports, abdominal surgeries, kidney stones and cyst ruptures also should be considered as causative factors for gross hematuria in ADPKD (Gabow et al 1992). The mean age of the first episode of gross hematuria in ADPKD is approximately 30 years (Gabow et al 1992). It should be noted that earlier onset of bleeding (ie, younger than 30 years), and more frequent episodes may indicate a risk of worsening renal function (Johnson and Gabow 1997). The incidence of gross hematuria is related to both kidney size and hypertension (Gabow et al 1992). Usually these episodes are self-limited, lasting for 2-7 days, and are best treated with conservative management. However, in cases of prolonged bleeding accompanied by pain, renal complications including UTI and/or obstruction must be excluded (Gabow et al 1992). Pain associated with cyst rupture tends to be more localized. Compression of renal structures due to massive hemorrhage may cause radiating pain to shoulder or abdomen (Bajwa et al 2001). In severe 
cases of gross hematuria prolonged bed rest, hydration and analgesic administration are often needed. Usage of NSAIDs should be limited. Rarely is hematuria so serious and persistent as to necessitate either nephrectomy or renal arterial embolization. Embolization may cause a severe pain, thus a combination of pharmalogical agents (eg, NSAIDs and opioids), surgical interventions, or an epidural anesthesia may be needed (Ordan et al 1983).

\section{Chronic pain}

During the prolonged course of the ADPKD, cyst formation and progressive kidney enlargement may cause a dull, chronic pain. Larger renal volumes accompanied by asymmetric, hypertrophic lumbosacral muscle groups tend to be the source of mechanical back pain. Moreover, traction of the renal capsule, related to enlarging cysts, is another cause for chronic pain in ADPKD patients. As expected, severe chronic pain correlates with larger kidneys (Milutinovic et al 1990; Bajwa et al 2001). A sequential, approach to chronic pain should be employed. A complete, non-judgmental history taking is the first important step. The optional treatments consist of:

1. Physical therapy measures (heating pads, ice massage);

2. Psychobehavioral modification techniques;

3. Systemic analgesics;

4. Physical interventions such as:

a. transcutaneous electrical nerve stimulation (TENS),

b. autonomic plexus blockade,

c. neuromodulation by spinal cord stimulation,

d. neuraxial opioids and local anesthetics,

e. surgical decompression of kidney and liver cysts, and

f. hepatectomy (partial) and/or nephrectomy.

(Bajwa et al 2001, 2004). Initially the least toxic systemic analgesics, eg acetaminophen, should be administered. The recommended dose of acetaminophen in patients with renal disease is $500-650 \mathrm{mg}$ orally every six hours. It can be increased to $1000 \mathrm{mg}$ every four and six hours (Henrich et al 1996). Surgical or laparoscopic deroofing is a conventional procedure as an alternative pain management in the case of kidneys with several large cysts (Elashry et al 1996; Barr et al 1998). Sulikowski et al found pain relief after laparoscopic renal decortication in $80 \%$ of ADPKD patients after 1 year and $60 \%$ after 3 years (Sulikowski et al 2006). Recently a pilot study on 15 selected patients with ADPKD using 99\% ethanol to decompress renal cysts, showed successful results regarding patient's pain and disappearance of dominant large cysts (Singh and Mehrotra 2006). In spite of the small group of patients, this procedure should be considered as a safe, cost effective therapeutic option in patients suffering from chronic flank pain.

\section{Liver cysts}

Hepatic cysts are the most frequent extra-renal manifestations of ADPKD. The prevalence of liver cysts is between 75 to $90 \%$ among ADPKD patients (Milutinovic et al 1980; Runfeld et al 1985; Gabow, Johnson et al 1990; D'Agata et al 1994; Que et al 1995). Age is an independent factor on the prevalence of hepatic cysts. In addition to age, deterioration of renal function and gender also are risk factors for liver disease in patients with ADPKD. The occurrence of hepatic cysts in female patients range from $58 \%-75 \%$ while among male subjects the prevalence is from 42 to $62 \%$. It is believed that estrogen has a stimulatory effect on liver parenchyma and increases hepatic cyst volumes without a significant effect on renal volume. Findings of the largest size and number of hepatic cysts in multiparous women and postmenopausal female patients receiving hormone replacement therapy support this hypothesis (Gabow et al 1990; Sulikowski et al 2006). Patients with more severe renal disease and lower creatinine clearance may present with more liver cyst involvement (Gabow, Johnson et al 1990). It is of interest that polycystic liver disease may also occur in the absence of polycystic kidney disease (Que et al 1995).

Hepatomegaly is the common feature of hepatic complications in ADPKD. Most patients often remain asymptomatic; however, abdominal mass, pain, early satiety, nausea, and vomiting may occur as complications of longstanding ADPKD liver disease. It should be noted that liver functional tests are usually normal in ADPKD patients with liver involvement. In symptomatic patients, however, alkaline phosphatase and Gamma-glutamyl transferase (GGT) values may be elevated in 30\%-47\% and 60\%-70\%, respectively (Que et al 1995; Sherstha et al 1997). Despite the progressive nature of the cystic disease, the hepatic parenchyma retains its normal pattern and function (Everson et al 1988). Abdominal ultrasound and computer-assisted tomography (CT) are recommended methods for radiologic evaluations (Levine et al 1985; Everson et al 1988).

Acute hepatic complications are cyst infection and cyst hemorrhage. Right abdominal pain accompanied with fever in ADPKD patients could be result either from right kidney or liver cyst infection (Telenti et al 1990). Infected cysts account for $3 \%$ of morbidity and $2 \%$ of mortality in ADPKD patients (Grunfeld et al 1985). The incidence of bacteremia is high with infected liver cysts and is detected in about $63 \%$ of cases with positive blood cultures. The causative agents are usually 
Gram-negative organisms such as E.coli (Grunfeld et al 1985; Kwok and McDougall 1996), and infected liver cysts should be diagnosed and treated aggressively. In order to identify the microorganisms, blood and/or cyst fluid cultures should be employed. In contrast to renal cyst infections, both antibiotic therapy and percutaneous cyst drainage under ultrasound or CT guidance should be considered in infected liver cysts. The antibiotics administered should be capable of penetration into liver cysts, such as ciprofloxacin or amikacin. Additional studies are necessary to evaluate newer treatment methods including hepatic artery infusion of antibiotics (Matoba et al 2004). Cyst hemorrhage may mimic the symptoms of an infected liver. This is a rare complication, which can be diagnosed best by MRI.

Massively enlarged liver cysts may displace adjacent organs, including the gut, diaphragm, and abdominal wall, and are responsible for early satiety, abdominal hernias, uterine prolapse and dyspnea. Pain is the most disabling complication of chronic hepatic disease. Jaundice related to biliary compression by cysts has been reported. Portal hypertension may occur secondary to portal vein compression, but this is uncommon among ADPKD patients with liver cysts. Both jaundice and portal vein compression may need surgical decompression of cysts (Howard et al 1976; Simonetti et al 1993; Dmitrewski et al 1996; Misra et al 1999). Ascites and variceal bleeding are uncommon in the ADPKD patient with liver cysts, but when present investigation to rule out vascular thrombosis is indicated (Chauveau et al 1997). Huge liver cysts may obstruct hepatic venous outflow and cause the Budd-Chiari syndrome (Torres et al 1994). Several cases have been reported following bilateral nephrectomy in ADPKD patients (Torres et al 1994; Dioniso et al 1995; Dionisio et al 1997). Sclerotherapy with alcohol, resection or fenestration of the hepatic cyst wall may be helpful with hepatic venous occlusion caused by solitary enlarged cysts. In a study on 35 patients with hepatic cysts, the recurrence rate with these treatments after a 1-year follow up was 17\% (Simonetti et al 1993; van Sonnenberg et al 1994). Cyst aspiration and sclerosants to treat multiple cysts results in more failures with higher symptomatic recurrence risk (Simonetti et al 1993; van Sonnenberg et al 1994). In these subjects stenting procedures may reestablish hepatic venous patency and abolish the pressure gradient. Generally, however, liver transplantation must be considered (Yang et al 2004). As mentioned above, pain in ADPKD patients with liver cysts can become both physically and psychologically incapacitating. In most cases pharmacological agents are ineffective. In the presence of extreme disabling symptoms such as malnutrition and/or intolerable pain, surgical approaches should be employed (Bajwa et al 2001). Cyst fenestration and combined liver resection-fenestration are two different surgical strategies. Both laparatomy and laparoscopic fenestration have been performed. These techniques are more beneficial in superficial and large cysts. Because of adverse effects and particularly the higher incidence of recurrent symptoms with the cyst fenestration technique, combined resection-fenestration seems to be the best method to reduce/relieve pain in ADPKD patents with cystic liver involvement (Newman et al 1990; Kabbej et al 1996; Yang et al 2004).

\section{Intracranial aneurysms}

Intracranial aneurysms (ICAs) and rupture of intracranial aneurysms (RICAs) are critical extra-renal manifestations of ADPKD. In the general population the estimated prevalence of ICAs derived from autopsy studies is $1 \%-5 \%$. In contrast ICAs are seen in approximately $4 \%-11.7 \%$ of ADPKD patients (Chapman et al 1992, 1997; Rinkel et al 1998; The International Study of Unruptured Intracranial Aneurysms Investigators 1998; Wiebers et al 2003). More than 90\% of these aneurysms are less than $10 \mathrm{~mm}$ and over $70 \%$ less than $6 \mathrm{~mm}$ in diameter (Schievink 1997; The International Study of Unruptured Intracranial Aneurysms Investigators 1998). Familial clustering of aneurysms has been reported both in the general population and in ADPKD patients (Hutson et al 1993; Schievink 1997; Belz et al 2001). In the general population, the incidence of subarachnoid hemorrhage (SAH) resulting from a ruptured ICA is about $0.05 \%$ per year (Schievink 1997; Wijdicks et al 2005). The risk of SAH is approximately fivefold higher in ADPKD patients (Chievink et al 1992). It has been proven that previous SAH and size are of the most important factors determining the occurrence of an aneurysm rupture (The International Study of Unruptured Intracranial Aneurysms Investigators 1998; Brennan and Schwartz 2000; Juvela et al 2000). The International Study of Unruptured Intracranial Aneurysms (ISUIA) that included 1449 asymptomatic UIA patients has described that the risk of rupture in patients without a prior $\mathrm{SAH}$ is higher in the cases with aneurysms larger than $10 \mathrm{~mm}$. Also, it has shown that patients with a history of bleeding aneurysm were 10 times more at risk of hemorrhage (The International Study of Unruptured Intracranial Aneurysms Investigators 1998). The peak incidence of $\mathrm{SAH}$ in the general population is between 55 and 60 years (Greenberg 2000). Aneurysmal bleeding in ADPKD patients tends to occur at a younger age with a mean age of 
35-45 years (Chauveau et al 1994; Chapman et al 1993). RICAs are responsible for approximately $80 \%$ of SAH's. It has been shown that the mortality rate within 30 days after bleeding is almost 45\% (Johnston et al 1998). A high proportion of individuals surviving a SAH may experience serious disabilities. $4 \%-7 \%$ of deaths in patients with ADPKD are due to RICAs (Chapman et al 1997). An important concern in ADPKD patients with prior RICA is the recurrence of SAH. One study showed that $25 \%$ of ADPKD patients with a previous ICA developed a new ICA over a mean period of 11.4 years (Belz et al 2003). The increased frequency of ICA in ADPKD and the potential life-threatening complications has led to the screening of patients. A recent prospective 10-year follow-up study, conducted at the University of Colorado Health Sciences Center, demonstrated that among patients with ADPKD who had a previous negative imaging study, only a very small percentage $(2.6 \%)$ had a new finding after a mean of 9.8 year follow-up (Schrier et al 2004). These findings have been verified by another study on patients with small-unruptured ICAs $(<7 \mathrm{~mm}$ in diameter) detected by presymptomatic screening. The risk of growth and development of new aneurysms in these patients who underwent an imaging follow-up within 81 months and clinical follow-up of 92 months were low (Gibbs et al 2004). Therefore, which patients should be screened, remains controversial. Screening in the following sub group of patients is highly recommended: patients with positive family history of aneurysm or patients with a previous SAH, patients with high-risk occupations eg, pilots, patients with elective up-coming surgeries that might place the aneurysms at a higher risk of rupture and those who request screening. As mentioned above, SAH occurs earlier in ADPKD patients, thus the screening program for this group should start at a young age. Twenty years of age has been recommended for screening in high-risk patients (Chauvau et al 1994; Hughes and Becker 2003). Severe headache is the most prominent clinical presentation of ICAs. Many patients describe the headache as the "worst headache of their life" (Wijdicks et al 2005).

CT angiography (CTA) after a venous injection of a contrast agent, magnetic resonance angiography (MRA), and angiography by direct intra-arterial catheterization (catheter angiography) are the preferred imaging techniques for screening ICAs. Non-invasive procedures (CTA and MRA) are recommended as the first approach. Sensitivity and specificity is considerably higher in MRA rather than CT (sensitivity, 0.69-0.99; specificity, 1.00) (White et al 2001; Kouskours et al 2004).
The optimal management of intact or ruptured aneurysms has not been well understood. In general, observation, craniotomy with clipping, or endovascular occlusions with the use of detachable coils (coiling) are treatment strategies. It has been shown that orally administered nimodipine (60 mg every four hours for 21 days) after SAH will improve the outcomes (Barker and Ogilvy 1996). Incidentally discovered small aneurysms $(<10 \mathrm{~mm})$ need not to be treated. Close observation and regular periodic surveillances are necessary in these subjects. Although previously it was believed that clipping compared to coiling resulted in a lower recurrence rate (David et al 1999), recent studies have demonstrated that the use of coils tend to have a lower inpatient mortality rate, shorter hospital stay, and lower costs (Johnston et al 1999, 2000, 2001).

\section{References}

Anderson RJ, Miller PD, Linas SL, et al. 1979. Role of the renin-angiotensin system in hypertension of polycystic kidney disease. Mineral Electrolyte Metab, 2:137-41.

Anderson GA, Degroot D, Lawson RK. 1993. Polycystic renal disease. Urol, 42:358-64.

Bajwa ZH, Gupta S, Warfield CA, et al. 2001. Pain management in polycystic kidney disease. Kidney Int, 60:1631-44.

Bajwa ZH, Sial KA, Malik AB, et al. 2004. Pain patterns in patients with polycystic kidney disease. Kidney Int, 66:1561-9.

Bardaji A, Matinez-Vea A, Gutierrez C, et al. 1998. Left ventricular mass and diastolic function in normotensive young adults with autosomal dominant polycystic kidney disease. Am J Kidney Dis, 32:970-5.

Barker FG II, Ogilvy CS. 1996. Efficacy of prophylactic nimodipine for delayed ischemic deficit after subarachnoid hemorrhage: a metaanalysis. J Neurosurg, 84:405-14.

Barry J, Teichman JM, Hulbert JC. 1998. Role and long term results of laparoscopic decortication in solitary cystic and autosomal dominant polycystic kidney disease. J Urol, 159:702-5.

Belz MM, Hughes RL, Kaehny WD, et al. 2001. Familial clustering of ruptured intracranial aneurysms in autosomal dominant polycystic kidney disease. Am J Kidney Dis, 8:770-6.

Belz MM, Fick-Brosnahan GM, Hughes RL, et al. 2003. Recurrence of intracranial aneurysms in autosomal-dominant polycystic kidney disease. Kidney Int, 63:1824-30.

Bengtsson U, Hedman L, Svalander C. 1975. Adult type of polycystic kidney disease in a new-born child. Acta Med Scand, 197:447-50.

BennettWM, Elzinga LW, Pulliam JP, et al. 1985. Cyst fluid antibiotic concentration in autosomal dominant polycystic kidney disease. Am J Kidney Dis, 6:400-4.

Blyth H, Ockenden BG. 1971. Polycystic disease of kidney and liver presenting in childhood. J Med Genet, 8:257-84.

Brennan JW, Schwartz ML. 2000. Unruptured intracranial aneurysms: appraisal of the literature and suggested recommendations for surgery, using evidence-based medicine criteria. Neurosurgery, 47:1359-72.

Bretan PN Jr, Price DC, McClure RD. 1988. Localization of abscess in adult polycystic kidney by indium-111 leukocyte scan. Urology, 32:169-71.

Chapman AB, Thickman D, Gabow PA. 1990. Percutaneous cyst puncture in the treatment of cyst infection in autosomal dominant polycystic kidney disease. Am J Kidney Dis, 16:252-5.

Chapman AB, Schrier RW. 1991. Pathogenesis of hypertension in autosomal dominant polycystic kidney disease. Semin Nephrol, 11:653-60. 
Chapman AB, Rubinstein D, Hughes R, et al. 1991. Intracranial aneurysms in autosomal dominant polycystic kidney disease. $N$ Engl $\mathrm{J}$ Med, 327:916-20.

Chapman AB, Johnson AM, Gabow PA. 1993. Intracranial aneurysms in patients with autosomal dominant polycystic kidney disease: how to diagnose and who to screen. Am J Kidney Dis, 22:526-31.

Chapman AB, Johnson AM, Gabow PA, et al. 1994. Overt proteinuria and microalbuminuria in autosomal dominant polycystic kidney disease. $J$ Am Soc Nephrol, 5:1349-54.

Chapman AB, Johnson AM, Rainguet S, et al. 1997. Left ventricular hypertrophy in autosomal dominant polycystic kidney disease. $J \mathrm{Am}$ Soc Nephrol, 8:1292-7.

Chapman AB, Guay-Woodford LM, Grantham JJ, et al. 2003. Renal structure in early autosomal-dominant polycystic kidney disease (ADPKD): The Consortium for Radiologic Imaging Studies of Polycystic Kidney Disease (CRISP) cohort. Kidney Int, 64:1035-45.

Chauveau D, Pirson Y, Verellen-Dumoulin C, et al. 1994. Intracranial aneurysms in autosomal dominant polycystic kidney disease. Kidney Int, 45:1140-6.

Chauveau D, Grunfeld JP, Durand F, et al. 1997. Ascites in a polycystic patient. Nephrol Dial Transplant, 12:228-30.

Chen WC, Lee YH, Huang JK, et al. 1993. Experience using extracorporeal shock-wave lithotripsy to treat urinary calculi in problem kidneys. Urol Int, 51:32-8.

Chievink WI, Torres VE, Piepgras DG, et al. 1992. Saccular intracranial aneurysms in autosomal dominant polycystic kidney disease. $J$ Am Soc Nephrol, 3:88-93.

D’Agata ID, Jonas MM, Perez-Atayde AR, et al. 1994. Combined cystic disease of the liver and kidney. Semin Liver Dis, 14:215-28.

Dalgaard DZ. 1957. Bilateral polycystic disease of the kidneys. A follow up of 284 patients and their families. Acta Med Scand, 328:12-33.

Daudon M, Cohen-Solal F, Lacour B, et al. 2003. Lithiases et anomalies des voies urinaires: la composition des calculs est-elle indépendante de l'anomalie anatomique? [Urinary stones and urinary tract abnormalities. Is the stone composition independent of the anatomical abnormality?] Prog Urol, 13:1320-9.

David CA, Vishteh AG, Spetzler RF, et al. 1999. Late angiographic follow-up review of surgically treated aneurysms. J Neurosurg, 91:396-401.

Delakas D, Daskalopoulos G, Cranidis A. 1997. Extracorporeal shockwave lithotripsy for urinary calculi in autosomal dominant polycystic kidney disease. J Endourol, 11:167-70.

Dimitrakov D, Simeonov S. 1994. Studies on nephrolithiasis in patients with autosomal dominant polycystic kidney disease. Folia Med, 36:27-30.

Dionisio P, Caramello E, Bergia R, et al. 1995. Budd-Chiari syndrome following pretransplantation nephrectomy in an ADPKD patient with liver cysts. Contrib Nephrol, 115:163-6.

Dionisio P, Sessa A, Conte F, et al. 1997. Budd-Chiari syndrome following pretransplant mononephrectomy in an autosomal dominant polycystic kidney disease patient with liver cysts. Nephron, 75:109-11.

Dmitrewski J, Olliff S, Buckels JA. 1996. Obstructive jaundice associated with polycystic liver disease. HPB Surg, 10:117-20.

Ecder T, Edelstein CL, Chapman AB, et al. 1999. Reversal of left ventricular hypertrophy with angiotensin converting enzyme inhibition in hypertensive patients with autosomal dominant polycystic kidney disease. Nephrol Dial Transplant, 14:1113-16.

Ecder T, Chapman AB, Brosnahan GM, et al. 2000. Effect of antihypertensive therapy on renal function and urinary albumin excretion in hypertensive patients with autosomal dominant polycystic kidney disease. A J Kidney Dis, 35:427-32.

Ecder T, Schrier RW. 2001. Hypertension in autosomal-dominant polycystic kidney disease: early occurrence and unique aspects. J Am Soc Nephrol, 12:194-200.

Ecder T, Edelstein CL, Fick-Brosnahan G, et al. 2001. Diuretics versus angiotensin-converting enzyme inhibitors in autosomal dominant polycystic kidney disease. Am J Nephrol, 21:98-103.
Ecder T, Schrier RW. 2004. Hypertension and left ventricular hypertrophy in autosomal dominant polycystic kidney disease. Expert Review of Cardiovascular Therapy, 1477-9072.

Ecder T, Fick-Brosnahan G, Schrier RW. 2006. Polycystic kidney disease. In: Schrier RW ed. Diseases of the kidney and urinary tract, 8th edn. Philadelphia, PA: Lippincott Williams and Wilkins.

Elashry OM, Nakada SY, Wolf JS Jr, et al. 1996. Laparoscopy for adult polycystic kidney disease: A promising alternative. Am J Kidney Dis, 27:224-33.

Elles RG, Hodgkinson KA, Mallick NP, et al. 1994. Diagnosis of adult polycystic kidney disease by genetic markers and ultrasonograghy imaging in a voluntary family register. $J$ Med Genet, 31:115-20.

Ettinger A, Kahn PC, Wise HM Jr. 1969. The importance of selective renal angiography in the diagnosis of polycystic disease. $J$ Urol, 102:156-61.

Everson GT, Scherzinger A, Berger-Leff N, et al. 1988. Polycystic liver disease: Quantitation of parenchymal and cyst volumes from computed tomography images and clinical correlates of hepatic cysts. Hepatology, 8:1627-34.

Fick GM, Johnson AM, Strain JD, et al. 1993. Characteristics of very early onset autosomal dominant polycystic kidney disease. J Am Soc Nephrol, 3:1863-70.

Fick GM, Duley IT, Johnson AM, et al. 1994. The spectrum of autosomal dominant polycystic kidney disease in children. J Am Soc Nephrol, $4: 1654-60$.

Fick GM, Johnson AM, Hammond WS, et al. 1995. Causes of death in autosomal dominant polycystic kidney disease. J Am Soc Nephrol, 5:2048-56.

Fick GM, Tran ZV, Johnson AM, et al. 2001. Progression of autosomaldominant polycystic kidney disease in children. Kidney Int, 59:1654-62.

Fick-Brosnahan GM, Belz MM, McFann KK, et al. 2002. Relationship between renal volume growth and renal function in autosomal dominant polycystic kidney disease: a longitudinal study. Am J Kidney Dis, 39:1127-34

Gabow PA. 1990. Autosomal dominant polycystic kidney disease - more than a renal disease. Am J Kidney Dis, 16:403-13.

Gabow PA, Duley I, Johnson AM. 1992. Clinical profiles of gross hematuria in autosomal dominant polycystic kidney disease. Am J Kidney Dis, 20:140-3.

Gabow PA, Chapman AB, Johnson AM, et al. 1990. Renal structure and hypertension in autosomal dominant polycystic kidney disease. Kidney Int, 38:1177-80.

Gabow PA, Johnson AM, Kaehny WD, et al. 1990. Risk factors for the development of hepatic cysts in autosomal dominant polycystic kidney disease. Hepatology, 11:1033-7.

Gabow PA, Kimberling WJ, Strain JD, et al. 1997. Utility of ultrasonograghy in the diagnosis of autosomal dominant polycystic kidney disease in children. J Am Soc Nephrol, 8:105-10.

Gabow PA, Johnson AM, Kaehny WD, et al. 1992. Factors affecting the progression of renal disease in autosomal-dominant polycystic kidney disease. Kidney Int, 41:1311-19.

Gambaro G, Fabris A, Puliatta D, et al. 2006. Lithiasis in cystic kidney disease and malformations of the urinary tract. Urol Res, 34:102-7. Epub 2006 Jan 14.

Garel L, Sauvegrain J, Filiatrault D. 1983. Dominant polycystic disease of the kidney in a newborn child. Report of one case. Ann Radiol (Paris), 26:183-6.

Gibbs GF, Huston J 3rd, Qian Q, et al. 2004. Follow-up of intracranial aneurysms in autosomal-dominant polycystic kidney disease. Kidney Int, 65:1621-7.

Grampsas SA, Chandhoke PS, Fan J, et al. 2000. Anatomic and metabolic risk factors for nephrolithiasis in patients with autosomal dominant polycystic kidney disease. Am J Kidney Dis, 36:53-7.

Grantham JJ, Torres VE, Chapman AB, et al. 2006. Volume progression in polycystic kidney disease. $N$ Engl J Med, 354:2122-30.

Grantham JJ, Torres VE, Chapman AB, et al. 2006. Volume progression in polycystic kidney disease. $N$ Engl J Med, 354:2122-30. 
Greenberg MS. 2000. SAH and aneurysms. In: Greenberg MS, ed. Handbook of neurosurgery. 5th ed. New York: Thieme Medical. p. 754-803.

Grunfeld JP, Albouze G, Jungers P, et al. 1985. Liver changes and complications in adult polycystic kidney disease. Adv Nephrol Necker Hosp, 14:1-20.

Harris PC, Bae KT, Rossetti S, et al. 2006. Cyst number but not the rate of cystic growth is associated with the mutated gene in autosomal dominant polycystic kidney disease. J Am Soc Nephrol, 17:3013-19. Epub 2006 Oct 11.

Henrich WL, Agodoa LE, Barrett B, et al. 1996. Analgesics and the kidney: summary and recommendations to the Scientific Advisory Board of the National Kidney Foundation from an Ad Hoc Committee of the National Kidney Foundation. Am J Kidney Dis, 27:162-5.

Hetherington JW, Philp MH 1986. Diclofenac sodium versus pethidine in acute renal colic. Br Med J, 292:237-8.

Hjelmesaeth J, Hartmann A. 1999. Insulin resistance in patients with adult polycystic kidney disease. Nephrol Dial Transplant, 14:2521-2.

Hossack KF, Leddy CL, Johnson AM, et al. 1988. Echocardiographic findings in autosomal dominant polycystic kidney disease. $N$ Engl $J$ Med, 319:907-12.

Howard RJ, Hanson RF, Delaney JP. 1976. Jaundice associated with polycystic liver disease. Relief by surgical decompression of the cysts. Arch Surg, 111:816-17.

Hughes PD, Becker GJ. 2003. Screening for intracranial aneurysms in autosomal dominant polycystic kidney disease. Nephrology (Carlton), 8(4):163-70.

Hutson J, Torres VE, Sullivan PP, et al. 1993. Value of magnetic resonance angiography for the detection of intracranial aneurysms in autosomal dominant polycystic kidney disease. J Am Soc Nephrol, 3:1871-7.

Ivy DD, Shaffer EM, Johnson AM, et al. 1995. Cardiovascular abnormalities in children with autosomal dominant polycystic kidney disease. $J \mathrm{Am}$ Soc Nephrol, 5:2032-6.

Johnson AM, Gabow PA. 1997. Identification of patients with autosomal dominant polycystic kidney disease at highest risk for endstage renal disease. J Am Soc Nephrol, 8:1560-7.

Johnston SC, Dudley RA, Gress DR, et al. 1999. Surgical and endovascular treatment of unruptured cerebral aneurysms at university hospitals. Neurology, 52:1799-805.

Johnston SC, Selvin S, Gress DR. 1998. The burden, trends, and demographics of mortality from subarachnoid hemorrhage. Neurology, $50: 1413-18$

Johnston SC, Wilson CB, Halbach VV, et al. 2000. Endovascular and surgical treatment of unruptured cerebral aneurysms: comparison of risks. Ann Neurol, 48:11-19.

Johnston SC, Zhao S, Dudley RA, et al. 2001. Treatment of unruptured cerebral aneurysms in California. Stroke, 32:597-605.

Jones DB. 1974. Arterial and glomerular lesions associated with severe hypertension. Light and electron microscopic studies. Lab Invest, 31:303-13.

Juvela S, Porras M, Poussa K. 2000. Natural history of unruptured intracranial aneurysms: probability of and risk factors for aneurysm rupture. J Neurosurg, 93:379-87.

Kabbej M, Sauvanet A, Chauveau D, et al. 1996. Laparoscopic fenestration in polycystic liver disease. Br J Surg, 83:1697-701.

Kaye C, Lewy PR. 1974. Congenital appearance of adult-type (autosomal dominant) polycystic kidney disease. J Pediatr, 85:807-10.

Kelleher CL, McFann KK, Johnson AM, et al. 2004. Characteristics of hypertension in young adults with autosomal dominant polycystic kidney disease. Am J Hypertens, 17:1029-34.

Kimberling WJ, Kumar S, Gabow PA, et al. 1993. Autosomal dominant polycystic kidney disease: Localization of the second gene to chromosome 4q13-q23. Genomics, 18:467-72.

Kouskouras C, Charitanti A, Giavroglou C, et al. 2004. Intracranial aneurysms: evaluation using CTA and MRA: correlation with DSA and intraoperative findings. Neuroradiology, 46:842-50.

Kwok CG, McDougall IR. 1996. Persistent fever in a patient with polycystic kidney and liver diseases and bilateral hip prostheses. $J$ Nucl Med, 37:2062-5.
Leier CV, Baker PB, Kilman JW, et al. 1984. Cardiovascular abnormalities associated with adult polycystic kidney disease. Ann Intern Med, 100:683-8.

Lembo G, Napoli R, Capaldo B, et al. 1992. Abnormal sympathetic over activity evoked by insulin in the skeletal muscle of patients with essential hypertension. $J$ Clin Invest, 90:24-9.

Leoncini G, Sacchi G, Ravera M, et al. 2002. Microalbuminuria is an integrated marker of sub-clinical organ damage in primaryhypertension. J Hum Hypertens, 16:79-89. Review.

Leoncini G, Viazzi F, et al. 2002. Microalbuminuria identifies overall cardiovascular risk in essential hypertension: an artificial neural network-based approach. J Hypertens, 20:1315-21.

Levine E, Cook LT, Grantham JJ. 1985. Liver cysts in autosomal-dominant polycystic kidney disease: clinical and computed tomographic study. AJR Am J Roentgenol, 145:229-33.

Levine E, Grantham JJ. 1992. Calcified renal stones and cyst calcifications in autosomal dominant polycystic kidney disease: clinical and CT study in 84 patients. AJR Am J Roentgenol, 159:77-81.

Loghman-Adham M, Soto CE, Inagami T, et al. 2004. The intrarenal reninangiotensin system in autosomal dominant polycystic kidney disease. Am J Physiol Renal Physiol, 287:F775-88.

Lumiaho A, Pihlajamaki J, Hartikainen J, et al. 2003. Insulin resistance is related to left ventricular hypertrophy in patients with polycystic kidney disease type 1. Am J Kidney Dis, 41:1219-24.

Martinez-Vea A, Bardaji A, Gutierrez C, et al. 1999. Echocardiographic evaluation in patients with autosomal dominant polycystic kidney disease and end-stage renal disease. Am J Kidney Dis, 34:264-72.

Martinez-Vea A, Valero FA, Bardaji, et al. 2000. A Left ventricular hypertrophy in hypertensive patients with autosomal dominant polycystic kidney disease: influence of blood pressure and humoral and neurohormonal factors. Am J Nephrol, 20:193-200.

Matoba M, Tonami H, Kuginuki M, et al. 2004. Intermittent hepatic artery antibiotic infusion therapy for pyogenic hepatic abscess. Acta Radiol, 45:13-17.

Mcdonald RA, Watkins SL, Avner ED, 1999. Polycystic kidney disease in Pediatric Nephrology, 4th ed. Edited by Barratt TM, Avner ED, Harmon W, Baltimore, Lippincott, Williams and Wilkins. p. 459-74.

McIntire SC, Rubenstein RC, Gartner JC, et al. 1993. Acute flank pain and reversible renal dysfunction associated with nonsteroidal antiinflammatory drug use. Pediatrics, 92:459-63.

Milutinovic J, Fialkow PJ, Rudd TG, et al. 1980. Liver cysts in patients with autosomal dominant polycystic kidney disease. Am J Med, 68:741-4.

Milutinovic J, Fialkow PJ, Agodoa LY, et al. 1984. Autosomal dominant polycystic kidney disease: Symptoms and clinical findings. $Q J \mathrm{Med}$, 53:511-22.

Milutinovic J, Fialkow PJ, Agodoa LY, et al. 1990. Clinical manifestations of autosomal dominant polycystic kidney disease in patients older than 50 years. Am J Kidney Dis, 15:237-43.

Misra A, Loyalka P, Alva F. 1999. Portal hypertension due to extensive hepatic cysts in autosomal dominant polycystic kidney disease. South Med J, 92:626-7.

Newman KD, Torres VE, Rakela J, et al. 1990. Treatment of highly symptomatic polycystic liver disease. Preliminary experience with a combined hepatic resection-fenestration procedure. Ann Surg, 212:30-7.

Nicolau C, Torra R, Badenas C, et al. 1999. Autosomal dominant polycystic kidney disease types 1 and 2: assessment of US sensitivity for diagnosis. Radiology, 213:273-6.

O'Neill WC, Robbin ML, Bae KT, et al. 2005. Sonographic assessment of the severity and progression of autosomal dominant polycystic kidney disease: the Consortium of Renal Imaging Studies in Polycystic Kidney Disease (CRISP). Am J Kidney Dis, 46:1058-64.

Oosterlinck W, Philip NH, Charig C, et al. 1990. A double blind single dose comparison of intramuscular ketorolac, tromethamine and pethidine in the treatment of renal colic. J Clin Pharmacol, 30:336-41.

Ordan GH, Babcock NC, Mocnik JJ, et al. 1983. Pain control following renal infarction/ablation using continuous epidural combined anesthesia/analgesia. J Urol, 130:861-2. 
PKD Foundation 2000, Polycystic Kidney Disease: The Most Common Life-Threatening Genetic Disease; Kansas City, Polycystic Kidney Research Foundation.

Pontremoli R, Leoncini G, Ravera M, et al. 2002. Microalbuminuria, cardiovascular, and renal risk in primary hypertension. J Am Soc Nephrol, 13:S169-72.

Pretorius DH, Lee ME, Manco-Johnson ML, et al. 1987. Diagnosis of autosomal dominant polycystic kidney disease in utero and in the young infant. J Ultrasound Med, 6:249-55.

Que F, Nagorney DM, Gross JB Jr, et al. 1995. Liver resection and cyst fenestration in the treatment of severe polycystic liver disease. Gastroenterology, 108:487-94.

Rinkel GJE, Djibuti M, Algra A, et al. 1998. Prevalence and risk of rupture of intracranial aneurysms: a systemic review. Stroke, 29:251-6.

Rocchini AP, Moorehead C, DeRemer S, et al. 1990. Hyperinsulinemia and the aldosterone and pressor responses to angiotensin II. Hypertension, 15:861-6.

Rovitch L, Lerman PH, Drabkin J. 1976. Ruptured renal cysts in polycystic disease. Urol, 7:60-1.

Runfeld JP, Albouze G, Jungers P, et al. 1985. Liver changes and complications in adult polycystic kidney disease. Adv Nephrol Necker Hosp, 14:1-20.

Schievink WI. 1997. Intracranial aneurysms. N Engl J Med, 336:28-40. Erratum, $N$ Engl J Med, 336:1267.

Schrier RW, McFann K, Johnson A, et al. 2002. Cardiac and renal effects of standard versus rigorous blood pressure control in autosomal dominant polycystic kidney disease: Results of a seven-year prospective randomized study. J Am Soc Nephrol, 13:1733-9.

Schrier RW, McFann KK, Johnson AM. 2003. Epidemiological study of kidney survival in autosomal dominant polycystic kidney disease. Kidney Int, 63:678-85.

Schrier RW, Johnson AM, McFann K, et al. 2003. The role of parental hypertension in the frequency and age of onset of hypertension in offspring with autosomal dominant polycystic kidney disease. Kidney Int, 64:1792-9.

Schrier RW, Belz MM, Johnson AM, et al. 2004. Repeat imaging for intracranial aneurysms in patients with autosomal dominant polycystic kidney disease with initially negative studies: a prospective ten-year follow-up. J Am Soc Nephrol, 15:1023-8.

Sedman A, Bell P, Manco-Johnson M, et al. 1987. Autosomal dominant polycystic kidney disease in childhood: a longitudinal study. Kidney Int, 31:1000-5.

Shamshirsaz AA, Bekheirnia MR, Kamgar M, et al. 2005. Autosomal dominant polycystic kidney disease in infancy and childhood: Progression and outcome. Kidney Int, 68:2218-24.

Sherstha R, McKinley C, Russ P, et al. 1997. Postmenopausal estrogen therapy selectively stimulates hepatic enlargement in women with autosomal dominant polycystic kidney disease. Hepatology, 26:1282-6.

Simonetti G, Profili S, Sergiacomi GL, et al. 1993. Percutaneous treatment of hepatic cysts by aspiration and sclerotherapy. Cardiovasc Intervent Radiol, 16:81-4.

Singh I, Mehrotra G. 2006. Selective ablation of symptomatic dominant renal cysts using $99 \%$ ethanol in adult polycystic kidney disease. Urology, 68:482-7; discussion 487-8.

Sklar AH, Caruana RJ, Lamers JE, et al. 1987. Renal infections in patients with adult polycystic kidney disease. Am J Kidney Dis, 10:81-8.

Sulikowski T, Kaminski M, Rozanski J, et al. 2006. Laparoscopic removal of renal cysts in patients with ADPKD as an alternative method of treatment and patient preparation for kidney transplantation: preliminary results. Transplant Proc, 38:23-7.
Sweet R, Keane WF. 1979. Perinephric abscess in patients with polycystic kidney disease undergoing chronic hemodialysis. Nephron, 23:237-40.

Taitz LS, Brown CB, Blank CE, et al. 1987. Screening for polycystic kidney disease: importance of clinical presentation in the newborn. Arch Dis Child, 62:45-9.

Taylor M, Johnson AM, Tison M, et al. 2005. Earlier diagnosis of autosomal dominant polycystic kidney disease: importance of family history and implications for cardiovascular and renal complications. Am J Kidney Dis, 46:415-23.

Telenti A, Torres VE, Gross JB Jr, et al. 1990. Hepatic cyst infection in autosomal dominant polycystic kidney disease. Mayo Clin Proc, 65:933-42.

The International Study of Unruptured Intracranial Aneurysms Investigators. 1998. Unruptured intracranial aneurysms - risk of rupture and risks of surgical intervention. $N$ Engl J Med, 339:1725-33.

Timio M, Monarca C, Pede S, et al. 1992. The spectrum of cardiovascular abnormalities in autosomal dominant polycystic kidney disease: a 10-year follow-up in a five-generation kindred. Clin Nephrol, $37: 245-51$.

Torres VE, Donovan KA, Scicli G, et al. 1992. Synthesis of renin by tubulocystic epithelium in autosomal-dominant polycystic kidney disease. Kidney Int, 42:364-73.

Torres VE, Erickson SB, Smith LH, et al. 1988. The association of nephrolithiasis and autosomal dominant polycystic kidney disease. $\mathrm{Am}$ J Kidney Dis, 11:318-25.

Torres VE, Rastogi S, King BF, et al. 1994. Hepatic venous outflow obstruction in autosomal dominant polycystic kidney disease. $J$ Am Soc Nephrol, 5:1186-92.

Torres VE, Wilson DM, Burnett JC, et al. 1991. Effect of inhibition of converting on renal hemodynamics and sodium enzyme management in polycystic kidney disease. Mayo Clin Proc, 66:1010-17.

Torres VE, Wilson DM, Hattery RR, et al. 1993. Renal stone disease in autosomal dominant polycystic kidney disease. Am J Kidney Dis, 22:513-19.

van Sonnenberg E, Wroblicka JT, D'Agostino HB, et al. 1994. Symptomatic hepatic cysts: Percutaneous drainage and sclerosis. Radiology, 190:387-92.

Wan SK, Cochlin DL. 1990. Sonographic and computed tomographic features of polycystic disease of the liver. Gastrointest Radiol, $15: 310-12$.

Watson ML, Macnicol AM, Allan PL, et al. 1992. Effects of angiotensin converting enzyme inhibition in adult polycystic kidney disease. Kidney Int, 41:206-10.

White PM, Teasdale EM, Wardlaw JM, et al. 2001. Intracranial aneurysms: $\mathrm{CT}$ angiography and MR angiography for detection prospective blinded comparison in a large patient cohort. Radiology, 219:739-49.

Wiebers DO, Whisnant JP, Huston J III, et al. 2003. Unruptured intracranial aneurysms: natural history, clinical outcome, and risks of surgical and endovascular treatment. Lancet, 362:103-10.

Wijdicks EF, Kallmes DF, Manno EM, et al. 2005. Subarachnoid hemorrhage: neurointensive care and aneurysm repair. Mayo Clin Proc 80:550-9.

Yang GS, Li QG, Lu JH, et al. 2004. Combined hepatic resection with fenestration for highly symptomatic polycystic liver disease: A report on seven patients. World J Gastroenterol, 10:2598-601. 
